\title{
Evaluating the Frequency of Use of Non-Projected Media Resources in the Teaching Geography in Public Secondary Schools in Koibatek Sub County
}

\begin{abstract}
Charles Kibet Kiptum* Egerton University, Kenya

Article History

Received: 29.08.2020

Accepted: 14.09 .2020

Published: 30.09 .2020

Journal homepage: https://www.easpublisher.com/easjhcs

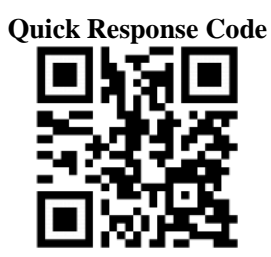

Abstract: This study sought to evaluate the frequency of use of non-projected media resources in the teaching Geography in public secondary schools in Koibatek Sub-County. A sample of 70 Geography teachers, 35 head teachers and 314 students were sampled using purposive and stratified random sampling. Data collection was done by use of questionnaires, observation and content analysis. Data was analyzed using descriptive statistical methods. The results were then presented in pie charts, graphs and tables. The study established that most schools had non-projected resources, though a limited supply and were rarely used. However, some schools lacked some important resources such as Geography rooms, facilities for field work, weather station and library services. Constraints emanating from heavy work load, heavy curriculum and inept administration were found to undermine to effective use of these resources in teaching Geography. The study has recommended for an urgent review of curriculum and increased supervision to ensure that curriculum is hilly implemented, and refresher courses be given to teachers on the use of these resources. Geography is one of subjects that can be studied as a physical or social science at high schools level. In secondary education it is currently an optional subject at upper secondary education. There have been concerns over declining performance in Geography at national examination, especially areas that test students' knowledge of field work, map work and physical Geography. Coincidentally these are the areas where nonprojected media resources are most used.

Keywords: Frequency, Non-projected media resources.
\end{abstract}

Copyright () 2020 The Author(s): This is an open-access article distributed under the terms of the Creative Commons Attribution 4.0 Internationa License (CC BY-NC 4.0) which permits unrestricted use, distribution, and reproduction in any medium for non-commercial use provided the original author and source are credited.

\section{INTRODUCTION}

This study focused on non-projected media resources in the teaching of Geography in public schools in Koibatek Sub-County, Kenya. Geography as a field of study helps society to make sense of the environment and further develops in them an understanding about why places differ (Kanjiru, 2014). The significance of Geography as among school going children is embedded in the fact that it enables them not only in understanding their environment but also how the environment can sustainably be used for the benefit of both present and future generations.

The pivotal role of non-projected media resources in the teaching of Geography is well documented by many scholars. Lang'at (2016) for instance, maintains that visual imagery for instructing provide authentic background, which helps to remove previously held misconceptions among the learners. Kanjiru (2014) have extended this by asserting that nonprojected media resources provides greater opportunities for stimulus variation, thereby creating a good learning environment in which students participate in finding out and interpreting what they observe. While some scholars have looked at these media resources because of the value they add in the teaching of Geography. More recently, due to increased financial pressure on government toward education following the introduction of free and compulsory primary education in 2003, the government has urged school administrators and respective instructors to creatively use locally available resources for effective teaching.

The field of Geography enables us to appreciate how places and landscapes are formed, how people and environments interact and associated consequences, and the interconnection between cultures and societies. Teaching resources in Geography include both projected and non-projected media. But despite the value non-projected media resources add to the understanding of Geography it has never been critically evaluated by many scholars as various studies and literature reveal. It is against this background that this study analyzed these media resources in terms of use in 
the teaching of Geography in public secondary schools in Koibatek Sub-County, Kenya.

\section{LITERATURE REVIEW}

Awino (2011) maintains that approaching to teaching Geography using these media resources introduces active learning as opposed to the traditional, passive acceptance of information that are characterized the teaching of this subject. This he argues helps students concretize abstract ideas, which in turn enhance their ability to develop self-reliance while sourcing for information. Furthermore, students are able to relate the acquired information to other relevant information in the curriculum arid hence deduce their ova interpretation.

While calling for use of media resources in Geography teaching Kanjiru (2014) asserts that these materials normally create some form of reality in the minds of students and help in the simplification of complex concepts in Geography, a view held by Unwin and McAleese (2011). He holds that abstract content of a message is easier to understand with the use of these media resources. All the above arguments underscore the need and value of media resources in the teaching of Geography.

Although the merits of using media resources in instruction are well documented, studies show that in practice, school teachers rarely utilize these items in teaching. These studies have established that the media resources for teaching Geography are either inadequate or unavailable and that the teachers are in fact less enterprising in this aspect of education than the case ought to be (Jeruto, 2018; Tuimur, \& Chemwei, 2015; Makokha, \& Wanyonyi, 2015; Lang'at, 2016). This situation may be attributed to many factors including negative teacher- attitudes towards the development and use of media resources, limited funding and lack of support from the ministry of education or school administration for Geography teachers in the development and use of the said materials.
Lang'at (2016) in his attempt to explain the absence and poor use of media resources in schools emphasizes that at the heart of this problem is the reluctance of the teachers to use media resources, irrespective of their quality of availability. He asserts that the teacher's perception of these materials is not related to the curriculum and that their use has not really penetrated the education sector to the point that they view them as necessary in teaching. He concludes by advising that teachers and especially Geography teachers should utilize media resources widely and effectively in instruction. And that they must be adequately trained in media education and pedagogy.

Non-projected media resources are teaching aids that facilitate the presentation of message that does not involve the projection on the screen. The examples of these teaching aids include chalkboards, maps, graph papers, charts, specimens, Geography rooms, weather stations, models, museums, field work and still pictures, among others. These teaching aids are very important and necessary in the teaching of Geography.

\section{DiscUSSIONS}

The Frequency of Use of Non-Projected Media Resources in Teaching of Geography

The study's third objective sought to analyze the frequency of use of non-projected media resources in the teaching of Geography in public secondary schools in Koibatek Sub-County. The established frequencies were then measured against the guidelines given in the Geography curriculum by the ministry of education. It was further important to compare and contrast the responses as given by instructors and the students. Given a range of selected non-projected media resources to the teachers to state how often they used them, at interval of once a week, once in two weeks, once in three weeks, once a month and once a term. Figure 1 shows responses given by Geography teachers drawn from different public secondary schools. 


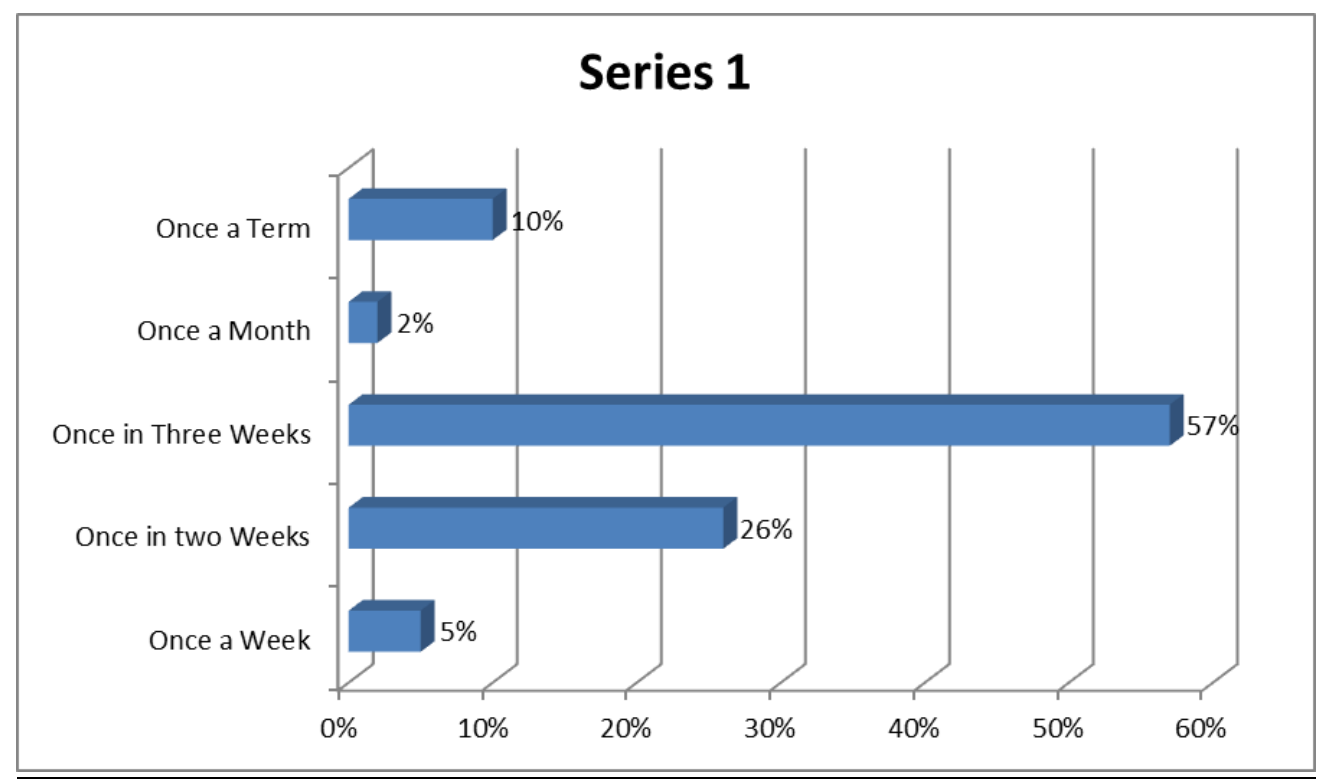

Figure 1: Number of Schools Frequently Using Selected Resources

The Geography teachers were targeted because subject teachers are the main players in the Geography teaching process and therefore better placed to respond to items concerned with frequency of use of nonprojected media resources in teaching of Geography. The students are the main players in the Geography learning process it was therefore important that they arc involved in the study.
When asked to state how often they used charts in Geography most students stated that they used them occasionally. This represented 48 per cent of the students. Other students mentioned that they used them rarely while other indicated that they had never used them at all. Those who stated that they used charts rarely were 33 per cent of the students compared to 1 per cent who said that they had never used charts at all in the study of Geography. Figure 2 represents various responses given by students on the frequency of charts.

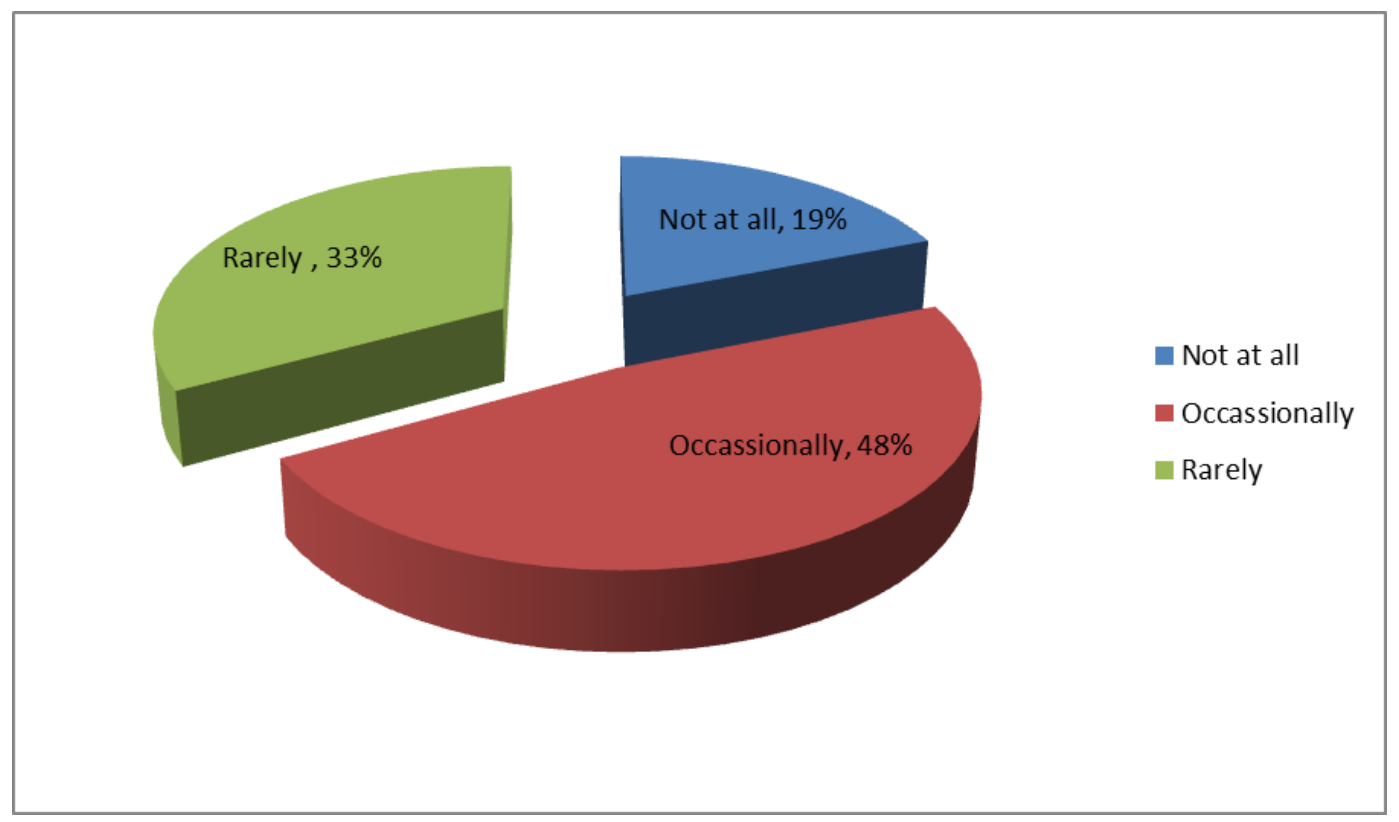

Figure 2: Frequency of Use of Charts According to Students

On graph papers, 47.1 per cent of Geography students stated that they occasionally used them. Those who indicated that they used them rarely were 42 per cent of Geography students. The rest of Geography students or 11 per cent of students noted that they had never used graph papers. These observations by Geography students are presented in Figure 3. 


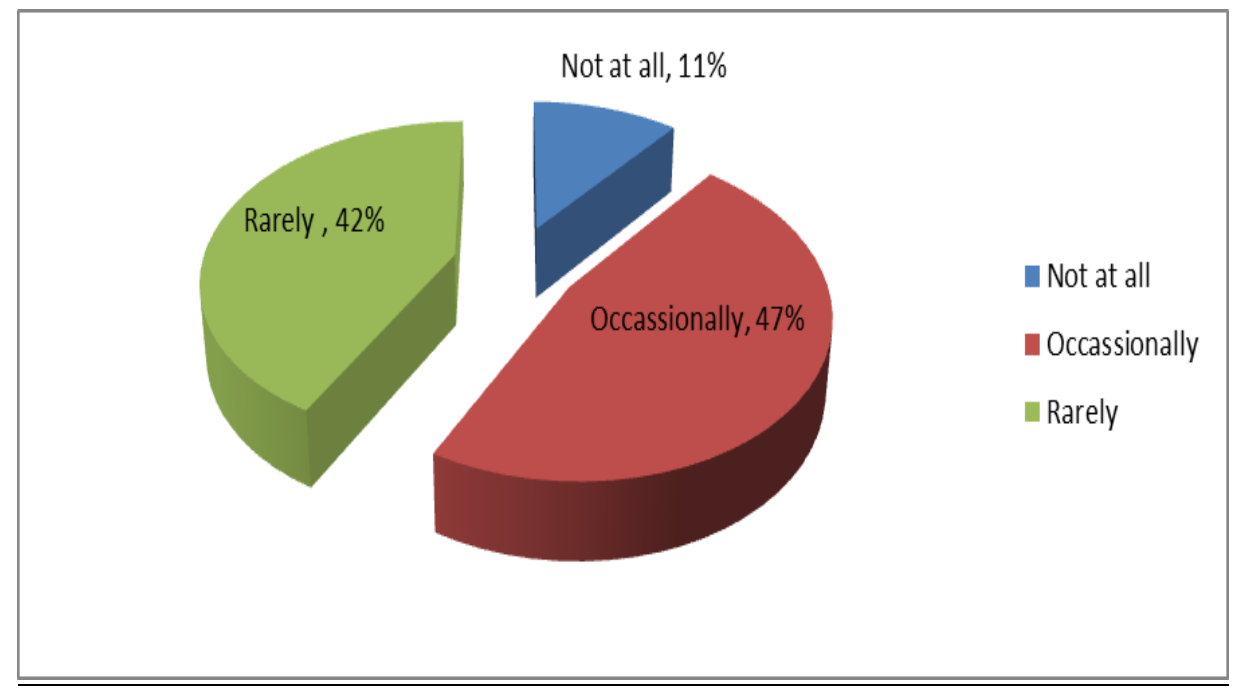

Figure 3: Frequency of Use of Graph Papers According to Students

Geography students who had never used specimens were 26 per cent of the students those who had used them occasionally and occasionally were 54 per cent and 20 per cent respectively these responses are illustrated in Figure 4.

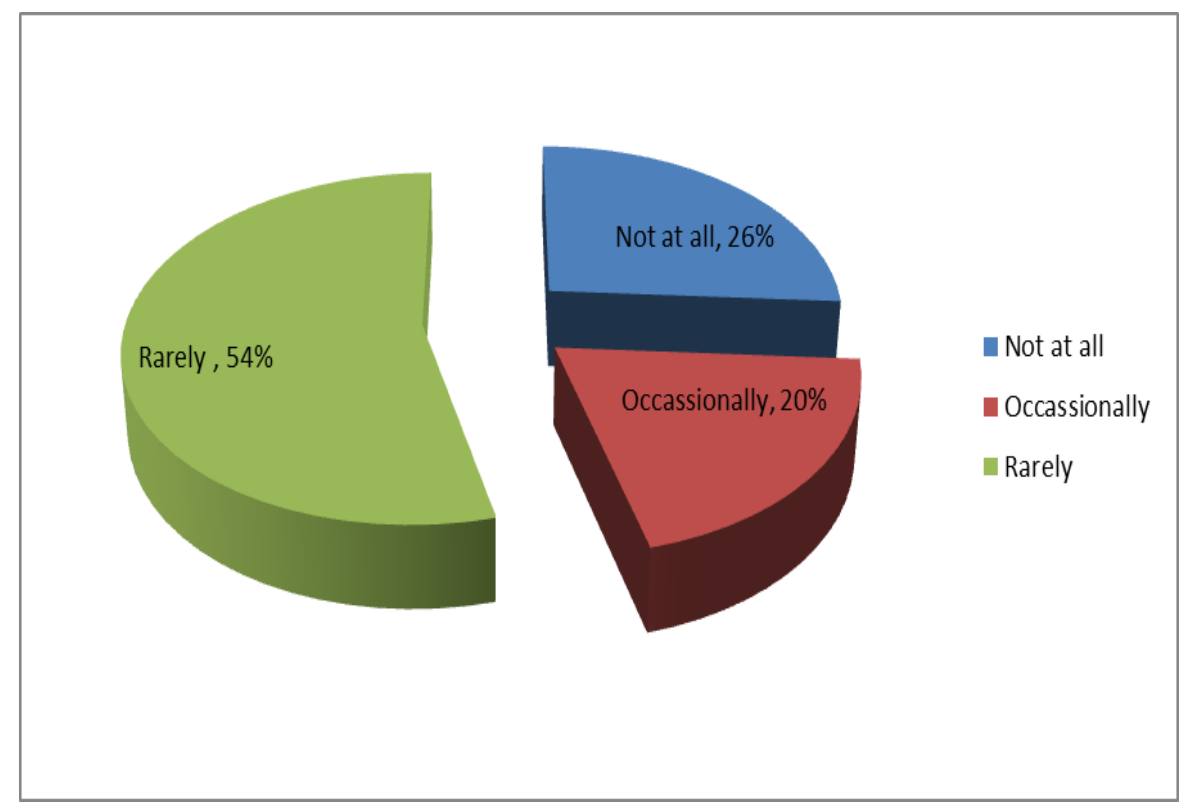

Figure 4: Frequency of Use of Specimens According to Students

As noted earlier, only a hand full of public secondary schools in Koibatek Sub-County had Geography rooms. It was thus important to find out how frequently they were used. When asked to state whether they had used Geography room occasionally, rarely or never used them at all, the students indicated the following. A large number of students or 57 per cent said rarely, 3 per cent indicated occasionally and 40 per cent pointed out that they had never used them at all. Consider Figure 5 for more illustration. 


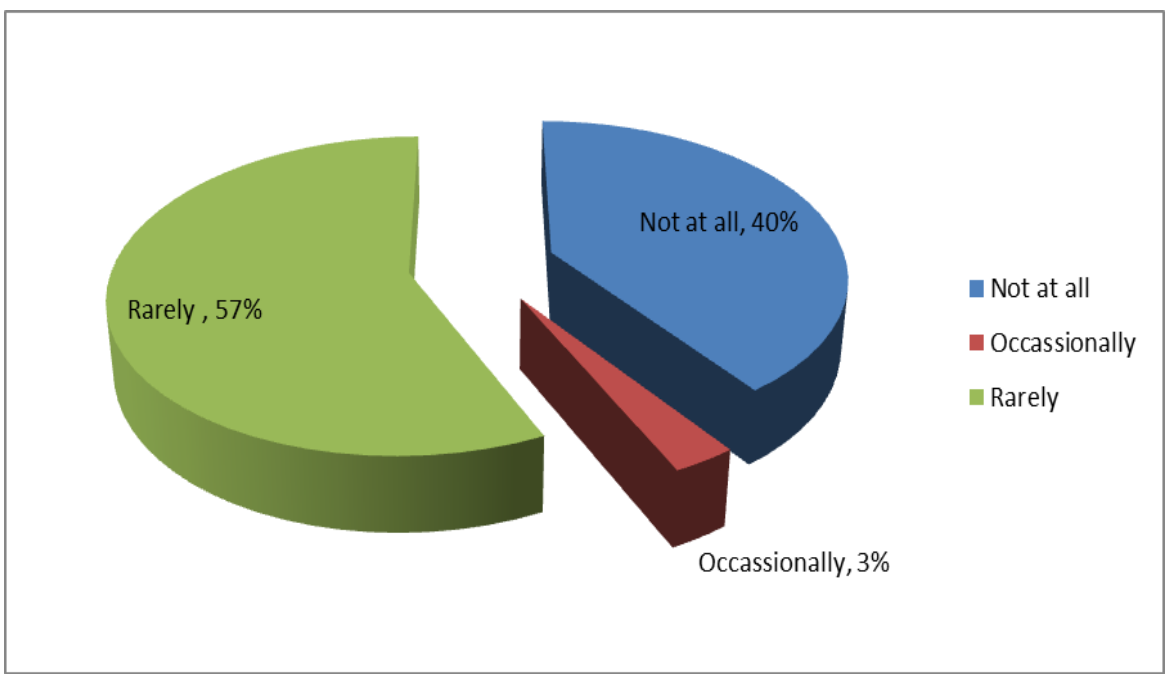

Figure 5: Frequency of Use of Geography Room According to students.

Weather station is one of the most important non-projected media resources used in teaching Geography. The frequency of its use was also investigated in this study. In schools where the facility was available, Geography students gave the following response with regard to the frequency of its use in
Geography teaching. Many students stated that they rarely used the facility. This accounted for 63 per cent of the respondents. Those who had used weather station occasionally and had never used it at all were 22 per cent and 15 per cent respectively.

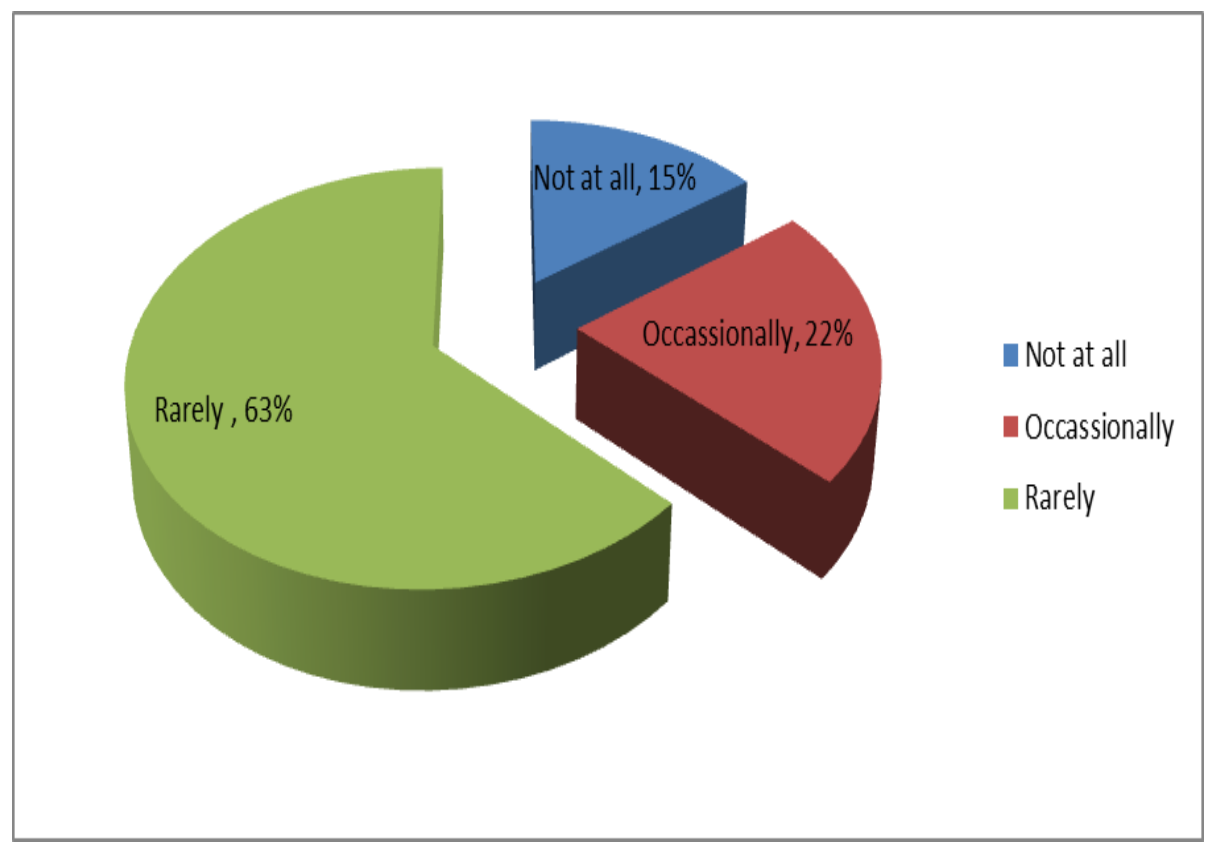

Figure 6: Frequency of Use of Weather Station According to Students

On community resources, 70 per cent of Geography students suggested that community resources were rarely used. Those who had used them occasionally and never used them all were 10 per cent and 20 per cent respectively. 


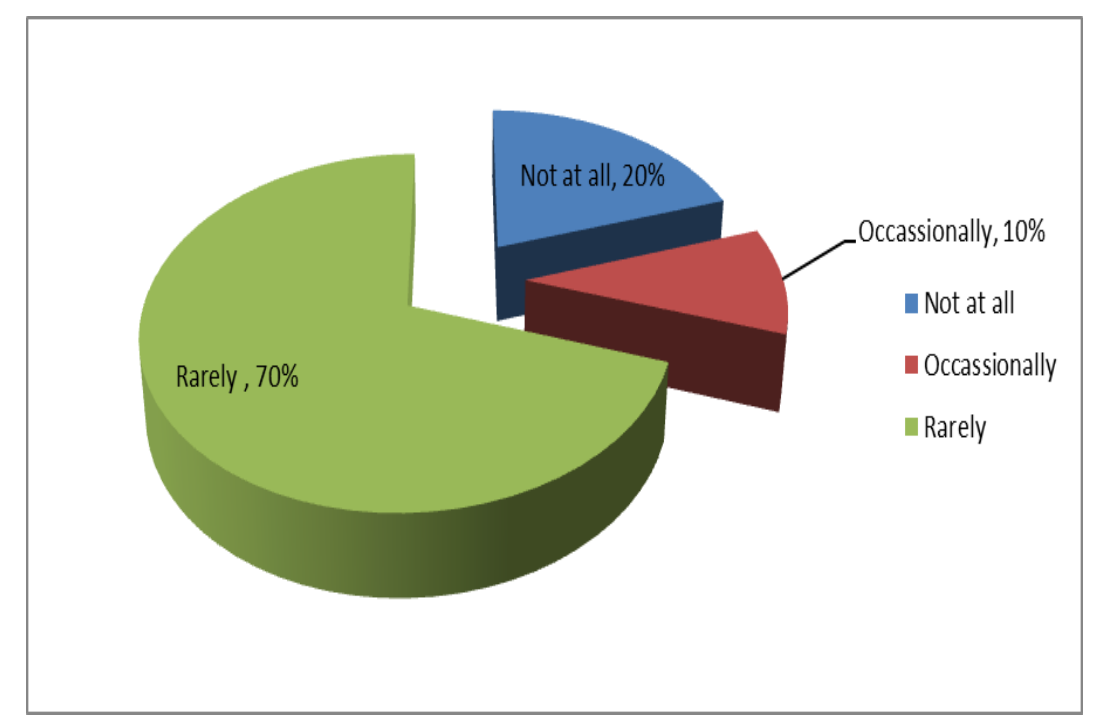

Figure 7: Frequency of Use of Community Resources According to Students

In summary, Geography students considered most of the non-projected media resources as rarely used. However, they felt that chalkboards, text books and diagrams were frequently used in the teaching of Geography. Another observation made here is that some non-projected media resources were used occasionally, while others had not been used at all. It is important to observe that even where non-projected media resources were available some students stated that they had never used them at all. While it was not within the scope of the current study to establish why they were not used even where they were available, the study has noted that it was not just the unavailability that constrains their utilization but other factors currently known to the study. The under-utilization of teaching resources is not new as earlier research by Lang'at, (2016) had revealed widespread use of teaching and learning resources in schools both tertiary institutions.

\section{CONCLUSION}

AND

\section{RECOMMENDATION \\ Conclusion}

While some schools had non-projected media resources that were largely lacking in most schools, they were rarely used in the teaching of Geography. Such resources as weather stations, Geography rooms and school bus were available in some schools but grossly under-utilized as most students indicated that they either used rarely, with some stating that they had never used them at all. There is need to increase the diversity of these resources and stricter supervision of their use by secondary schools in the Sub-County enforced if poor performance arising from their underutilization is to be curtailed.

\section{Recommendation}

For better understanding of Geography concepts and skills, frequency use of non-projected media is paramount in the teaching of Geography. The study thus recommends an evaluation of training methodology in training institutions by ministry of education to ascertain whether insufficient skills is a problem emanating from their initial training of teachers. It should then make appropriate changes to ensure that future products of these training institutions have sufficient skills and appropriate attitude towards the use of non-projected media resources Geography teaching. There is need for induction of teachers, where glaring skill constraints are evident, on the use of nonprojected media resources in the teaching of Geography.

\section{REFERENCES}

1. Awino, O. E. (2011). Instructional methods for composition writing in French at secondary school level in Nairobi, Kenya. Nairobi: Unpublished Masters $€^{\mathrm{TM}_{\mathrm{S}}}$ Thesis), Kenyatta University.

2. Jeruto, F. (2018). The Influence of Primary Teachers' Attitude towards Planning for Instruction in Nandi South Sub-County. African Journal of Education, Science and Technology, 1(4), 1-5. Retrieved from https://ajest.info/index.php/ajest/article/view/220

3. Kanjiru, G. E. (2014). Factors influencing students' Kenya certificate of secondary education performance in geography in Changamwe SubCounty, Mombasa County, Kenya. (Published Thesis, University of Nairobi).

4. Lang'at, C. (2016). Utilization of Instructional Resources in Teaching Practical Geography in Secondary Schools in Kipkelion Sub-County, Kericho County-Kenya. Retrieved from https://pdfs.semanticscholar.org/54ab/e07ee5f3244 3131a33f7650e482e327da61a.pdf

5. Makokha, R. N., \& Wanyonyi, K. M. (2015). The Utilization of Instructional Resources in Teaching Kiswahili Poetry in Secondary Schools in Kenya 
International Journal of Academic Research in Business and Social Sciences, 5(8), 10-18

6. Misoi, P. J. (2010). Rewards and Teachers' Performance among Secondary School of Baringo Sub-County, Kenya. Unpublished Thesis, Kampala International University.

7. Tuimur, H. N., \& Chemwei, B. (2015). Availability and Use of Instructional Materials in the Teaching of Conflict and Conflict Resolution in Primary Schools in Nandi North Sub-County, Kenya. International Journal of Education and Practice 3(6), 224-234.

8. Unwin, D., \& McAleese, R. (2011). The Encyclopedia of Educational Media Communication. Technology, London: McMillan Press. 